\title{
“NASCER EM BERÇO DE OURO”: O QUARTO INFANTIL COMO INSTÂNCIA SOCIALIZATÓRIA
}

\author{
Cibele Noronha de Carvalho ${ }^{1}$ \\ Maria Alice Nogueira²
}

\begin{abstract}
RESUMO: Este artigo apresenta parte de uma pesquisa realizada em quartos infantis de domicílios socioeconomicamente favorecidos. Diante da crescente importância desse cômodo, fenômeno que vem sendo chamado "cultura do quarto", a pesquisa analisou a materialidade e os sentidos conferidos por pais e crianças a esse espaço. Os procedimentos de investigação consistiram em entrevistas com os pais e produção de vídeos nos quais crianças entre 3 e 11 anos apresentavam seus quartos. Como resultado, foram encontrados: i) traços decorativos que apontam para o ideal educativo da autonomia e para uma socialização genderizada; ii) objetos que servem de suporte à rememoração de gerações anteriores; iii) decorações representativas de um ethos cosmopolita; e iv) móveis que conferem ao quarto feições de anexo da escola.
\end{abstract}

Palavras-chave: Socialização da criança. Arquitetura. Classe média e elite

\section{“FED WITH A SILVER SPOON": CHILDREN'S BEDROOM AS A SOCIALIZING INSTANCE}

\begin{abstract}
This article presents part of a research done on children's bedrooms in socioeconomically privileged households. Considering the increasing importance of this room, a phenomenon called "bedroom culture", the research analyzed the materiality and the senses given to these spaces by parents and children. As investigation procedures, we conducted interviews with the parents, and produced videos in which 3 to 11 -years old children presented their bedrooms. The outcomes were: i) decoration traces that pointed towards an educational ideal of autonomy and a genderized socialization; ii) objects that supported the memory of previous generations; iii) decorations representing a cosmopolitan ethos; and iv) pieces of furniture that give to the bedroom characteristics of a school annex.
\end{abstract}

Keywords: Children socialization. Architecture. Middle class and elite.

\footnotetext{
Este artigo se refere a pesquisa de doutorado realizada entre 2014 e 2018 na Faculdade de Educação da Universidade Federal de Minas Gerais, tendo como resultado, a tese "Nascer em berço de ouro": Os quartos infantis como instância de socialização de crianças pertencentes a estratos sociais favorecidos (CARVALHO, 2018)

1.Universidade Federal de Minas Gerais - Faculdade de Educação - Belo Horizonte (MG), Brasil. E-mail: cibbelecarvalho@gmail.com 2.Universidade Federal de Minas Gerais - Faculdade de Educação - Belo Horizonte (MG), Brasil. E-mail: malicen@terra.com.br
} 


\title{
“NACER EN UNA CUNA DE ORO”: LA HABITACIÓN INFANTIL COMO INSTANCIA DE SOCIALIZACIÓN
}

\begin{abstract}
RESUMEN: Este artículo presenta parte de una investigación realizada en habitaciones de niños y niñas que viven en hogares socioeconómicamente favorecidos. En vista de la creciente importancia de este lugar, un fenómeno que se conoce como "cultura del dormitorio", la investigación analizó la materialidad y los significados dados por padres e hijos a este espacio. Los procedimientos de investigación consistieron en entrevistas con los padres y la producción de videos por niños y niñas entre 3 y 11 años donde ellos presentaron sus habitaciones. Como resultado, encontramos: i) características decorativas que apuntan al ideal educativo de autonomía y a una socialización que considera el género; ii) objetos que recuerdan las generaciones anteriores; iii) decoraciones representativas de un ethos cosmopolita; y iv) los muebles hacen que la habitación parezca un anexo de la escuela.
\end{abstract}

Palabras-clave: Socialización en la infancia. Arquitectura. Clase media y élite

\section{Introdução}

$\mathrm{N}$

o Brasil, os Estudos da Infância têm sido majoritariamente voltados para as camadas populares (PRADO, 2017). Embora esse fato se justifique pela necessidade de evidenciar os problemas sociais que atingem as crianças desses grupos, a escassez de estudos sobre a infância nos estratos sociais superiores tem comprometido a adoção de uma perspectiva relacional nesse campo de estudos.

Este artigo apresenta parte de uma pesquisa realizada junto a essa última parcela da população, que, a despeito do déficit habitacional brasileiro, desfruta de condições materiais de existência que permitem dispor de um quarto para seus filhos e, não raro, de um quarto para cada filho. O objetivo era compreender como e em que medida o lugar destinado às crianças nos espaços domésticos afeta e reflete a socialização.

Se o quarto é tomado, nesta investigação, como objeto empírico, o objeto teórico éa socialização familiar das crianças das frações superiores e das elites. Essa sobreposição de objetos tem como ponto de partida dois pressupostos.

O primeiro é que "não basta nascer burguês, é preciso também aprender a sê-lo" (LE WITA, 1988, p. 5). Dito de outra forma, trata-se de distinguir o nascimento em uma família com alta posição na escala social do fato de ser inserido em uma cultura de classe, criar ou adquirir disposições socialmente herdadas, dominar esquemas mentais e ser capaz de significá-los e reproduzi-los. Essa cultura de classe é aqui compreendida como um estado, mas também como um processo de aquisição e interpretação individual socialmente modelado.

Além disso, essa sobreposição de objetos é alicerçada no pressuposto dos estudos da cultura material de que as moradias e os móveis articulam sentidos, discursos e representações, que são reinterpretados pelos sujeitos em um circuito comunicativo (CARVALHO, 2019) ${ }^{1}$. Assim, o ambiente doméstico é aqui compreendido de modo dialético; ou seja, como espaço, ao mesmo tempo, condicionante e condicionado - ou, segundo o conceito do antropólogo Daniel Miller (2001, 2010), um espaço em que coexistem a agência dos objetos e a acomodação das pessoas nos espaços.

Miller (2001) também compreende a casa como mercadoria e espaço de armazenamento de mercadorias. De alto custo, esse "elefante das coisas" é submetido a fortes relações de poder, que não permanecem somente no domínio público, mas atravessam também a soleira da porta, condicionando a maneira como as pessoas vivem, localizando os moradores socialmente e determinando como eles se distribuem pelos cômodos e que sentidos dão aos espaços. 
Por outro lado, há que se considerar também o esforço de apropriação da moradia realizado pelo morador - uma tentativa de chegar a um acordo com a agência da casa, tornando-a menos estranha e mais familiar. A esse trabalho de "sentir-se em casa", inevitavelmente experimentado nas mudanças residenciais, Miller (2001) chama "acomodação", palavra, aliás, que possui a mesma origem etimológica da palavra "cômodo". No entanto, diferentemente da apropriação de outros objetos de consumo, como as vestimentas, a acomodação em uma casa não é simples, mas sempre condicionada por uma variedade de fatores externos à relação entre morador e moradia, como as dinâmicas do espaço urbano e o mercado imobiliário.

$\mathrm{Na}$ investigação aqui abordada, essa perspectiva foi utilizada para investigar um cômodo residencial específico, que, apesar de nem sempre ter existido, é hoje considerado indispensável nas moradias urbanas contemporâneas: os quartos infantis. Sua emergência é decorrente da especialização dos ambientes domésticos (DIBIE, 1988) e do surgimento de um tipo de sensibilidade diferente em relação à infância (ELIAS, 2010). Por sua vez, sua crescente importância nas últimas décadas deve-se ao fato de que o principal espaço de lazer das crianças burguesas das grandes cidades foi deslocado dos espaços públicos para os familiares e daí para os espaços individualizados (BUCKINGHAN, 2007), que contam agora com a possibilidade de entretenimento oferecida pelas tecnologias de informação e comunicação (FRITH, 1978; LIVINGSTONE, 2002, 2007; CRUBELLIER, 1979; OPIE; OPIE, 1969; GLEVAREC, 2010). Essa nova relação da infância com o espaço doméstico, que implica emergência de um espaço para si, personalizado e multifuncional, tem sido chamada "cultura do quarto" (GLEVAREC, 2010).

Contudo, o conceito de uma cultura do quarto não deve escamotear as intrínsecas relações dos os espaços privados entre si, e, tampouco entre espaços privados e espaços públicos. Apesar de uma longa tradição, que consolidou uma visão excessivamente dicotômica entre a casa e a rua, o público e o privado (MARTUCCELLI, 2002), trata-se antes de perceber como a moradia é um artefato material em constante relação com a cidade. Assim, em vez de pensar a casa em termos estáticos, pesquisadores têm sugerindo a compreensão desse espaço a partir dos movimentos que os moradores fazem para dentro e para fora dela (CHRISTENSEN; O’BRIEN 2003), bem como a partir da relação que esses sujeitos estabelecem com a vizinhança e com o espaço público mais amplo.

Na pesquisa aqui relatada, foram realizadas 20 visitas a domicílios de famílias favorecidas de Belo Horizonte, tendo sido utilizados os seguintes instrumentos de coleta: (a) entrevistas semiestruturadas com pais e/ou mães; (b) produção de um vídeo em que a criança apresenta o próprio quarto; (c) produção de um esboço de planta a partir do aplicativo Magic Plan. Tais escolhas se orientaram para a adoção de métodos participativos, que levassem em consideração os interesses das crianças e os significados por elas atribuídos aos espaços e dinâmicas familiares (LANGE; MIERENDORFF, 2009; SEYMOUR; MCNAMEE, 2012).

Embora se pretendesse originalmente realizar a pesquisa com crianças entre 7 e 11 anos, a faixa etária do grupo pesquisado acabou variando entre 3 e 11 anos, uma vez que alguns caçulas pediram para participar da pesquisa, além de outros membros da fratria, que, mesmo menores de 7 anos, dividiam o quarto com irmãos pertencentes à faixa etária do critério de pesquisa. Assim, no total, participaram 31 crianças: 22 meninos e 9 meninas.

A investigação se deu em edifícios e condomínios fechados localizados em uma região periférica da cidade, para onde as elites têm se deslocado nas últimas décadas. Esse movimento autossegregativo carrega consigo o duplo objetivo de proteção contra a violência urbana, ao mesmo tempo que proporciona um ambiente seleto para o crescimento das crianças (CALDEIRA, 2000), aspecto bastante almejado por esse grupo social.

Um desses condomínios possui o sugestivo nome de "Grand Lider Olympus". Com 52.000 m², o Olympus oferece piscinas com borda molhada, quadras e salões de festas em cada uma de suas nove torres; uma praça central de $4.500 \mathrm{~m}^{2}$, com lagoa e cascata artificiais; pista para cooper; golf executivo; putting green (pista de golf para tacadas de curto alcance); e driving range (pista para tacadas de distância). Na descrição dos equipamentos de lazer, chamam atenção o valor dado aos materiais (borda molhada); o provimento do espaço (praça central de $4.500 \mathrm{~m}^{2}$ ); e o uso de termos em inglês para a descrição de espaços destinados a práticas esportivas consideradas altamente distintivas. 
No que diz respeito à segurança, o condomínio oferece guarita blindada, segurança perimetral, circuito fechado de TV, porteiros e seguranças, além de central de alarme em cada um dos apartamentos, compondo um conjunto de equipamentos que são detalhadamente descritos no site de divulgação desse empreendimento imobiliário como um diferencial do edifício. Essa forte atenção dada aos equipamentos de segurança configura o que a urbanista e pesquisadora de condomínios brasileiros Tereza Caldeira (2000) denomina "estética da segurança”. Para ela, esse modelo habitacional assume a forma de uma cidade entre muros, ou de enclaves fortificados ${ }^{2}$, portando uma relativa autonomia cultural, que permite a esse grupo social converter em valor estético distintivo um volumoso aparato de segurança, compreendido como necessário diante da real violência urbana.

Do ponto de vista socioeconômico, as famílias pesquisadas situam-se nos mais altos estratos da hierarquia social brasileira, acumulando diversos tipos de capitais. De tamanho reduzido, elas acompanham as alterações demográficas que sinalizam a redução do tamanho da família brasileira - a qual passou de 5,8 filhos por casal, em 1970, para uma média de 2 filhos por casal nos últimos anos (IBGE, 2017). Esses dados talvez ajudem a explicar o fato de que a totalidade dos pais respondentes da pesquisa declara ter dividido quarto com seus irmãos, ao passo que, entre as 31 crianças participantes da pesquisa, 25 possuem quarto exclusivamente para si e apenas 6 partilham o quarto com irmão ou irmã (Tabela 1).

Tabela 1. Crianças participantes.

\begin{tabular}{|c|c|c|}
\hline Nome (e irmãos) & Idade (anos) & Posição na fratria \\
\hline 1. $\quad$ Fernando (a irmã não participou) & 11 & Caçula \\
\hline 2. Ana Beatriz (o irmão não participou) & 08 & Primogênita \\
\hline 3. Ana Laura (o irmão não participou) & 11 & Caçula \\
\hline 4. Daniel (irmão de Tiago) & 09 & Primogênito \\
\hline 5. Tiago (irmão de Daniel) & 05 & Caçula \\
\hline 6. Isabel (irmã de Leandro) & 08 & Primogênita \\
\hline 7. Leandro (irmão de Isabel) & 06 & Caçula \\
\hline 8. $\quad$ Paulo (irmão de Laís) & 08 & Primogênito \\
\hline 9. $\quad$ Laís (irmã de Paulo) & 06 & Caçula \\
\hline 10. Cauã & 11 & Filho único \\
\hline 11. Daniele (irmã de Leopoldo e Murilo) & 09 & Primogênita \\
\hline 12. Leopoldo (irmão de Daniele e Murilo) & 06 & Filho do meio \\
\hline 13. Murilo (irmão de Daniele e Leopoldo) & 03 & Caçula \\
\hline 14. Ítalo (irmão de Sabrina) & 07 & Primogênito \\
\hline 15. Sabrina (irmã de Îtalo) & 04 & Caçula \\
\hline 16. Abelardo (o irmão não participou) & 09 & Caçula \\
\hline 17. Gabriel (irmão de Henrique e Camila) & 08 & Primogênito \\
\hline 18. Henrique (irmão de Gabriel e Camila) & 07 & Filho do meio \\
\hline 19. Camila (irmã de Gabriel e Henrique) & 03 & Caçula \\
\hline 20. João (irmão de Pedro) & 09 & Primogênito \\
\hline 21. Pedro (irmão de João) & 05 & Caçula \\
\hline 22. Joaquim (o irmão não participou) & 09 & Caçula \\
\hline 23. Davi (as irmãs não participaram) & 07 & Primogênito \\
\hline 24. Clara & 10 & Filha única \\
\hline 25. Gustavo & 09 & Filho único \\
\hline 26. Leonardo (irmão de Lucas) & 08 & Primogênito \\
\hline 27. Lucas (irmão de Leonardo) & 04 & Caçula \\
\hline 28. Paulo & 11 & Filho único \\
\hline 29. Larissa (irmã do Daniel) & 10 & Primogênita \\
\hline 30. Daniel (irmão da Larissa) & 07 & Caçula \\
\hline 31. Tiago & 07 & Filho único \\
\hline
\end{tabular}




\section{A Agência dos Espaços e Objetos}

Com bastante espaço disponível, a maior parte dos quartos visitados é multifuncional, e a nomenclatura "quarto de dormir" já não dá conta da diversidade de atividades que ocorrem nesse cômodo. Além de lugar de guardar os pertences das crianças e espaço de brincar, parte dos quartos visitados funciona também como um anexo da escola (ESTABLET, 1987). Nas famílias de classe média alta (mais do que nas famílias de elite), escrivaninhas, globos terrestres, mapas e estantes de livros sinalizam a importância atribuída à escola por esses grupos (NOGUEIRA, 2010) (Fig. 1).

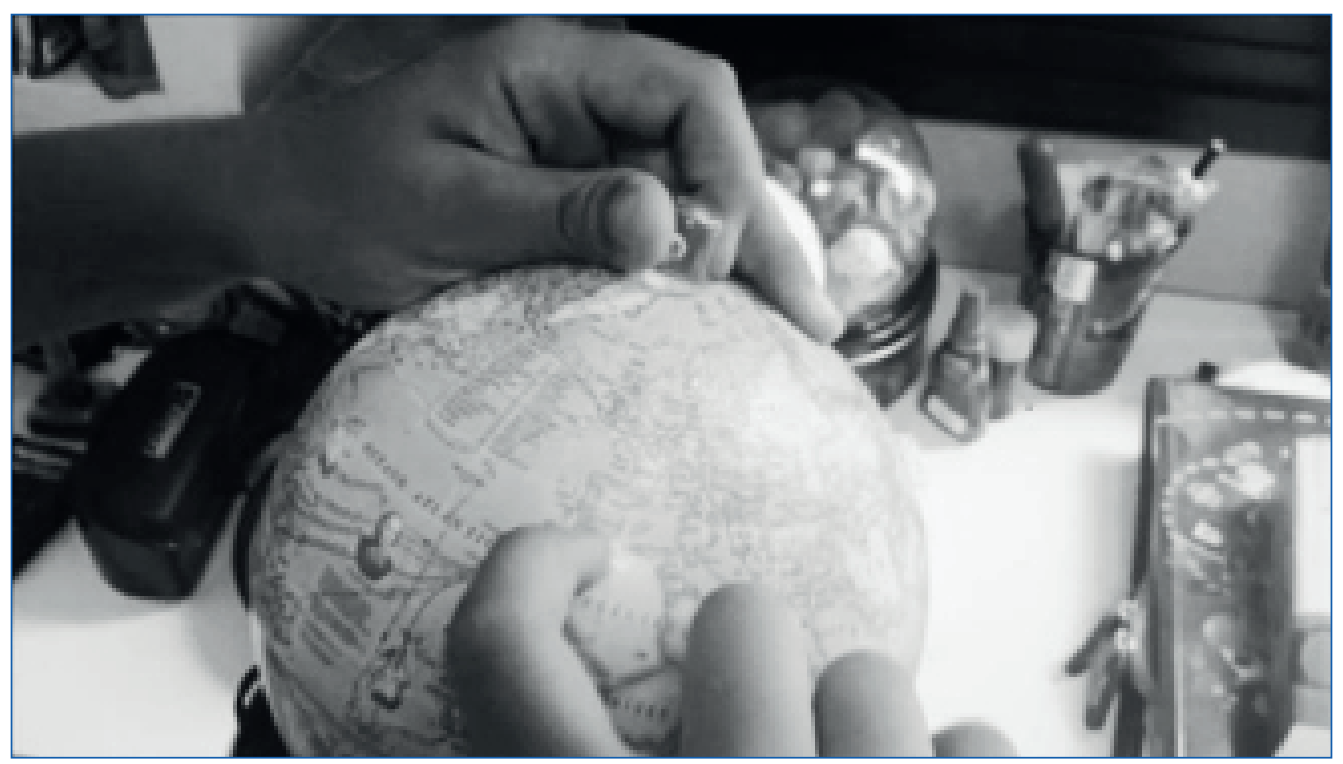

Figura 1. Globo terrestre que mostra o trajeto das Cruzadas do século XII.

Essa pedagogização do cotidiano permite pensar no efeito que a reserva desse espaço privativo para os estudos pode exercer sobre o rendimento escolar, provocado, evidentemente, pelas condições materiais que ele garante, além de ser efeito do próprio investimento, simbólico e afetivo, que materializa, no espaço, as aspirações educativas dos pais.

Além disso, na condição de um espaço exclusivo, ocupado por um tempo estendido, os quartos possibilitam a experiência da autonomia e da privacidade - ideais educativos que têm se mostrado particularmente caros às classes mais favorecidas (KELLERHALS et al., 1991). Não é difícil imaginar que contar com um espaço pessoal dentro do espaço familiar produza efeitos na construção de disposições das crianças de camadas privilegiadas dessa geração:

Não conhecer a promiscuidade no cotidiano é uma experiência que deve ter relação com a naturalidade com que as pessoas bem-nascidas colocam em cena seus corpos nas inter-relações sociais. Do mesmo modo, é esse lugar ocupado na sociedade que é interiorizado, ao mesmo tempo que essas relações com o espaço (PINÇON; PINÇON-CHARLOT, 2000, p. 87).

Se, por um lado, os quartos de dormir dos estratos favorecidos passaram a ser espaços em que a criança pode usufruir de sua privacidade, construir sua autonomia e expressar sua personalidade, por outro, é inegável que esses espaços refletem o investimento material, educativo e emocional dos pais, podendo também ser compreendidos como espaço de criação familiar (SEGALEN; LE WITA, 1993). Como bem demonstra o endereçamento das matérias jornalísticas de decoração ao público feminino, são as mães, em geral, que coparticipam 
mais ativamente da decoração do quarto do filho ou da filha. É delas, também, a responsabilidade de gerenciar, arquivar e selecionar as fotos, "objetos-lembrança” e documentos que contam a história da criança (FINE et al., 1993).

Gustavo tem 9 anos e é filho de pais separados com guarda compartilhada. Tanto na casa do pai quanto na casa da mãe, ele possui um quarto individual, ambos visitados por ocasião da pesquisa de campo; mas é no quarto da casa materna que se encontram os objetos que contam a história de Gustavo. Também é a mãe quem recorre ao álbum de bebê, guardado em sua casa, para mostrar como era o berço em que Gustavo dormia.

Tiago, 7 anos, apresenta-me seu quarto sem mostrar a parede com fotos de sua primeira infância. Quando lhe pergunto sobre esse canto, ele explica: “Aí estão as fotos que a mamãe costuma colocar [...]”. (Fig. 2).

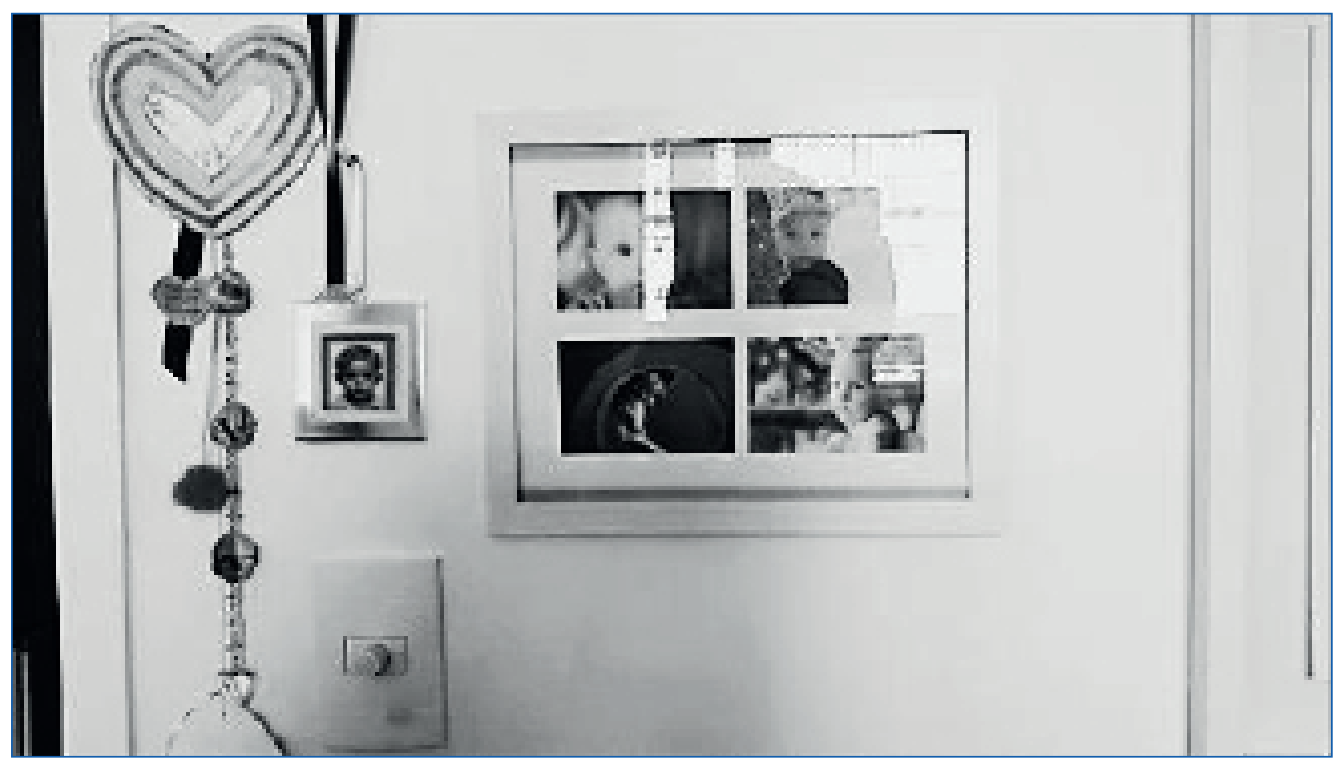

Figura 2. Parede de lembranças decorada pela mãe no quarto de Tiago.

Além de conter objetos que narram a história da própria criança, alguns quartos contam a história das gerações precedentes. Abelardo, 9 anos, possui uma caixa de lembranças. Sobre prateleiras, que são chamadas pelo menino de "central da bagunça", fica exposta a caixa onde guarda "algumas coisas especiais", como a carteira de piloto de avião do avô (Fig. 3).

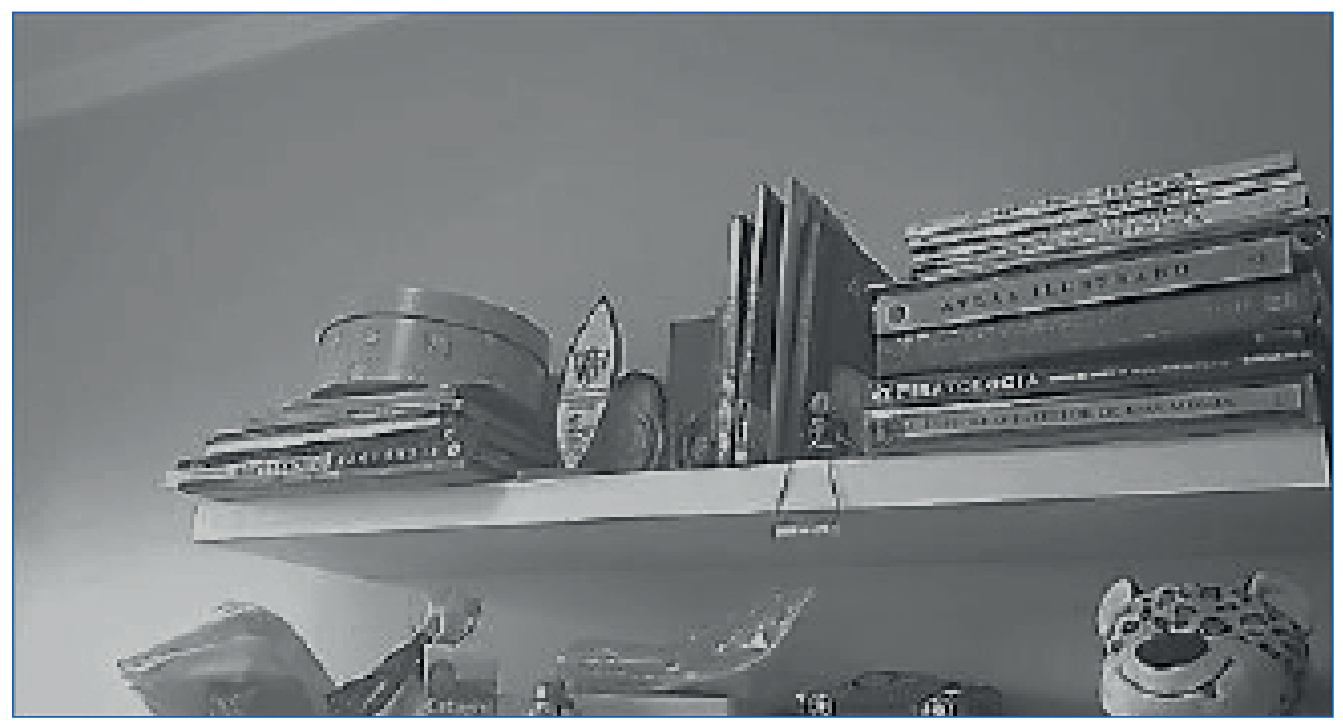

Figura 3. Caixa de lembranças do quarto de Abelardo. 
No quarto de Fernando, 6 anos, encontra-se um móvel baixo de madeira, onde estão arranjados diversos objetos, entre os quais os troféus de hipismo do pai e uma balança que foi presente do avô.

Vale lembrar que toda herança material é, também, uma herança simbólica (BOURDIEU, [1979] 2016), podendo os objetos do quarto atuar como suporte, não apenas para a memória da própria criança, mas também para a rememoração estendida às gerações anteriores. (Figs. 4 e 5).

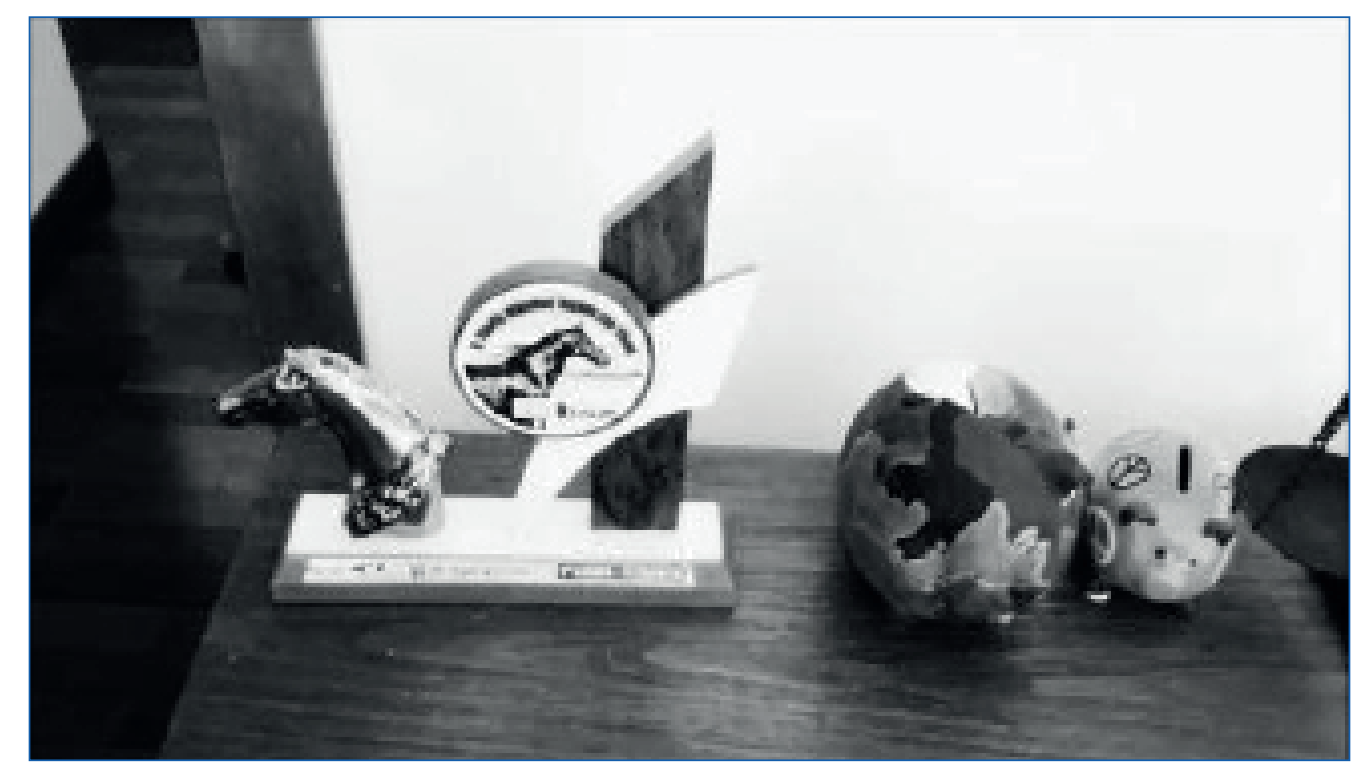

Figura 4. Troféu do pai de Fernando, ao lado de dois cofrinhos.

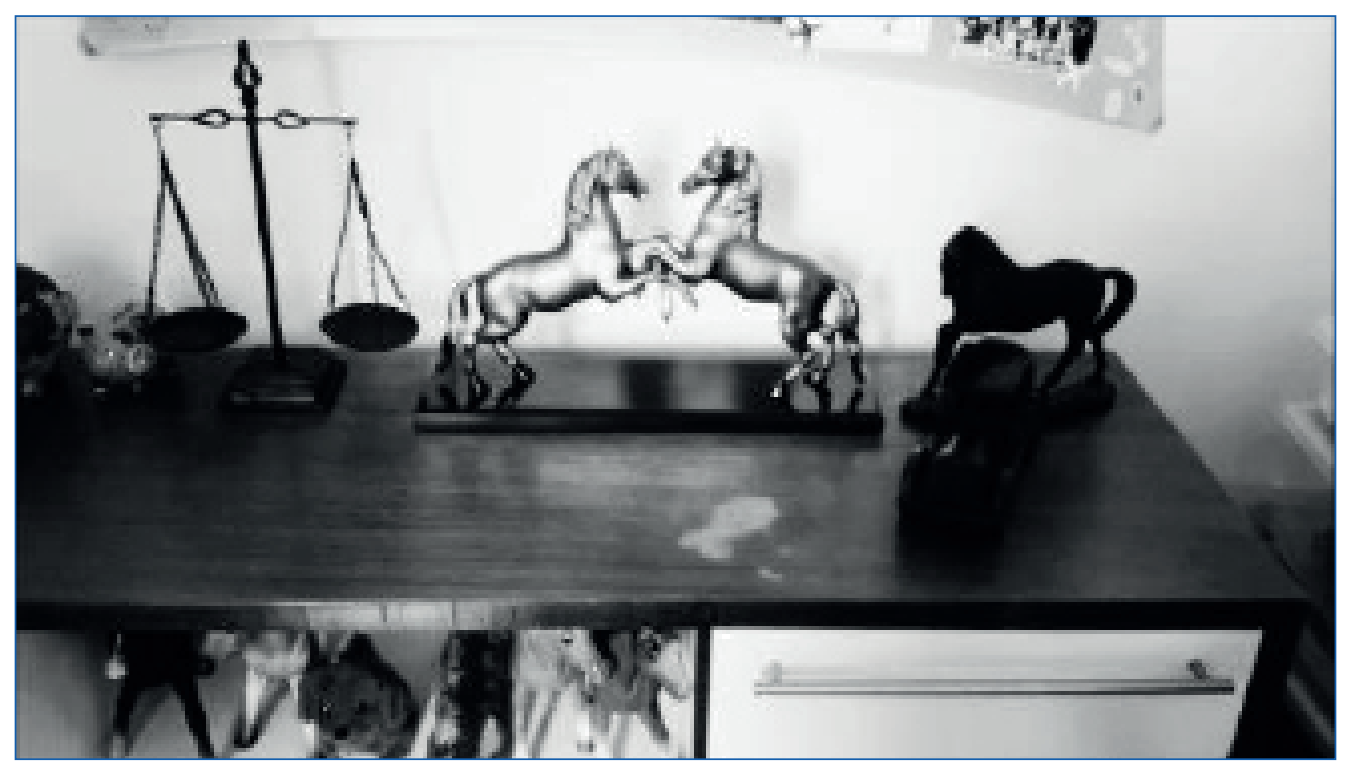

Figura 5. A balança, símbolo do direito, presente do avô de Fernando

Algumas pesquisas realizadas na França demonstram que, ao descrever seus antepassados, indivíduos pertencentes aos estratos superiores da sociedade conseguem evocar gerações mais distantes do que indivíduos oriundos dos grupos menos favorecidos (SINGLY; THÉLOT, 1986; LE WITA, 1983). A razão disso é que, para as famílias de classes média e superior estabelecidas, além de inegável fonte de afeto, a memória tem um uso social: ela distingue os grupos em ascensão dos grupos que possuem capitais acumulados há algumas gerações. 
Assim, na medida em que a história dos antepassados detentores de capitais é permanentemente recontada, ela se torna memória coletiva do grupo e, por isso mesmo, mais facilmente evocada. A relativa estabilidade dos espaços e dos objetos contribui de modo bastante contundente para essa rememoração, de tal forma que as casas de família e seus móveis, passados de geração para geração, oferecem a esse grupo "a imagem pacificante de sua continuidade" (HALBWACHS, 1997, p. 159).

Em uma obra sobre a socialização primária das crianças da aristocracia francesa, entre o final do século XIX e a primeira metade do XX, Éric Mension-Rigau (1990) chama esse fácil trânsito pelo passado de "domínio do tempo". Compreendido como característico da cultura dessa classe social, o controle do tempo é potencializado pelo domínio do espaço; ou seja, pelo sentimento de que o mundo está "ao alcance das mãos".

Sobretudo em relação às crianças moradoras de condomínios brasileiros, é senso comum a afirmação de que elas são espacialmente confinadas. No entanto, os relatos das famílias mostram que elas desfrutam de muita mobilidade pelo condomínio, pela cidade e fora dela, além de experimentarem diversos meios de transporte, embora pouco andem a pé e quase nunca desacompanhadas.

Na cidade de Belo Horizonte, nos últimos anos, tem sido comum a realização, nesses estratos sociais, de festas infantis "em trânsito". Seja em uma boatebus ou em uma luxuosa limusine, as crianças comemoram com os amigos dentro de um veículo em circulação, com parada em pontos da cidade para fotos. Assim, a mobilidade, mais do que o confinamento, é que parece caracterizar a socialização dessas crianças, para quem o domínio do espaço é favorecido por práticas multiespaciais. No entanto, esses diversos deslocamentos não garantem a essas crianças vivências e relações diversificadas. Ao contrário: embora os deslocamentos sejam intensos, os espaços frequentados são, assim como os condomínios, fortemente selecionados e monitorados. Seguindo a mesma lógica do "estar entre os iguais", a frequência a tantos espaços homogêneos tem por efeito a "ilusão de frequentar todos os lugares" (PINÇON; PINÇON-CHARLOT, 2000); tratando-se de um confinamento que é mais sociocultural do que espacial.

Se, durante a semana, os deslocamentos se devem às inúmeras atividades escolares e paraescolares e, nos fins de semana, ocorrem para permitir a vida no campo, as férias são momentos destinados às viagens nacionais e internacionais. Assim, não é raro encontrar, sobre camas ou prateleiras, as pelúcias adquiridas em viagens (Figs. 5 e 6 ).

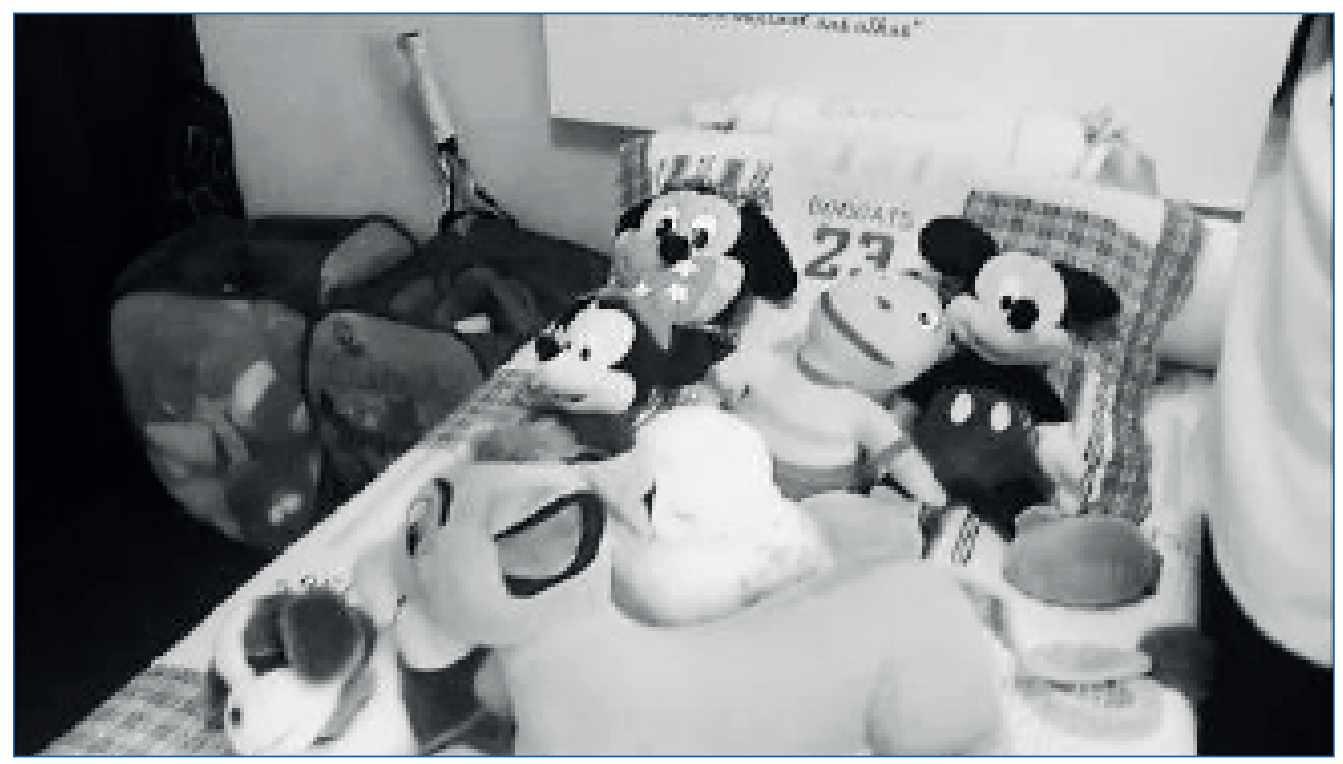

Figura 6. Pelúcias de viagem do quarto de Abelardo, 9 anos. 


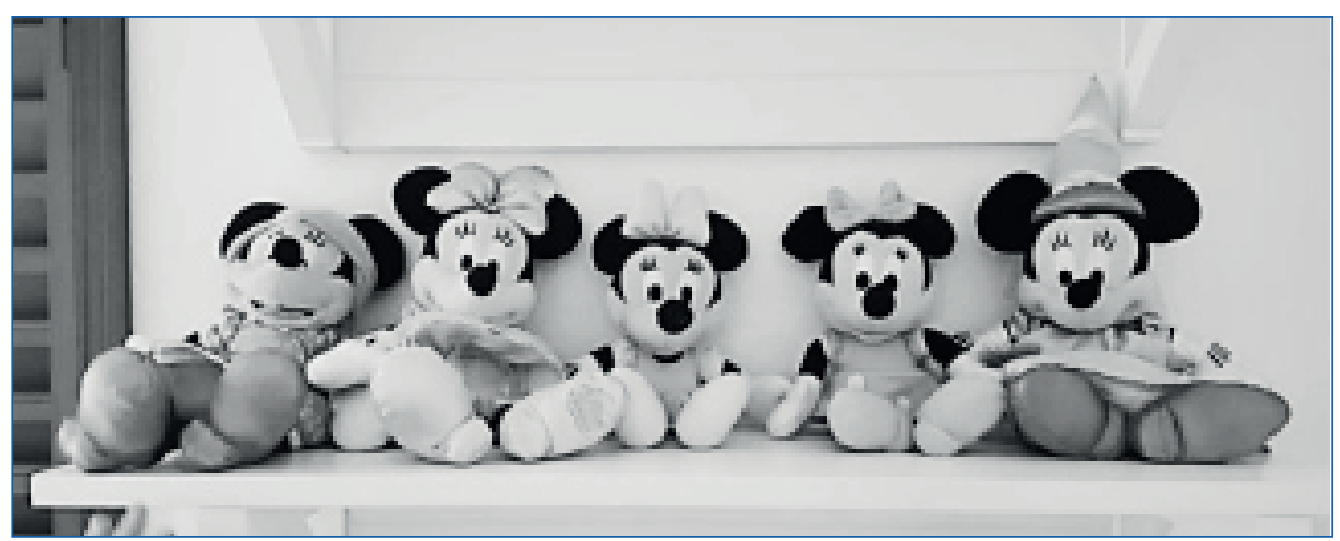

Figura 7. Pelúcias do quarto de Ana Beatriz, 8 anos.

No quarto de Vítor, 8 anos, além de inúmeros objetos que fazem referência a outras culturas, sobretudo à cultura inglesa, o ethos cosmopolita revestiu até mesmo as paredes do quarto, na forma de um papel de parede estampado com o nome de capitais de inúmeros países (Figs. 8 e 9).

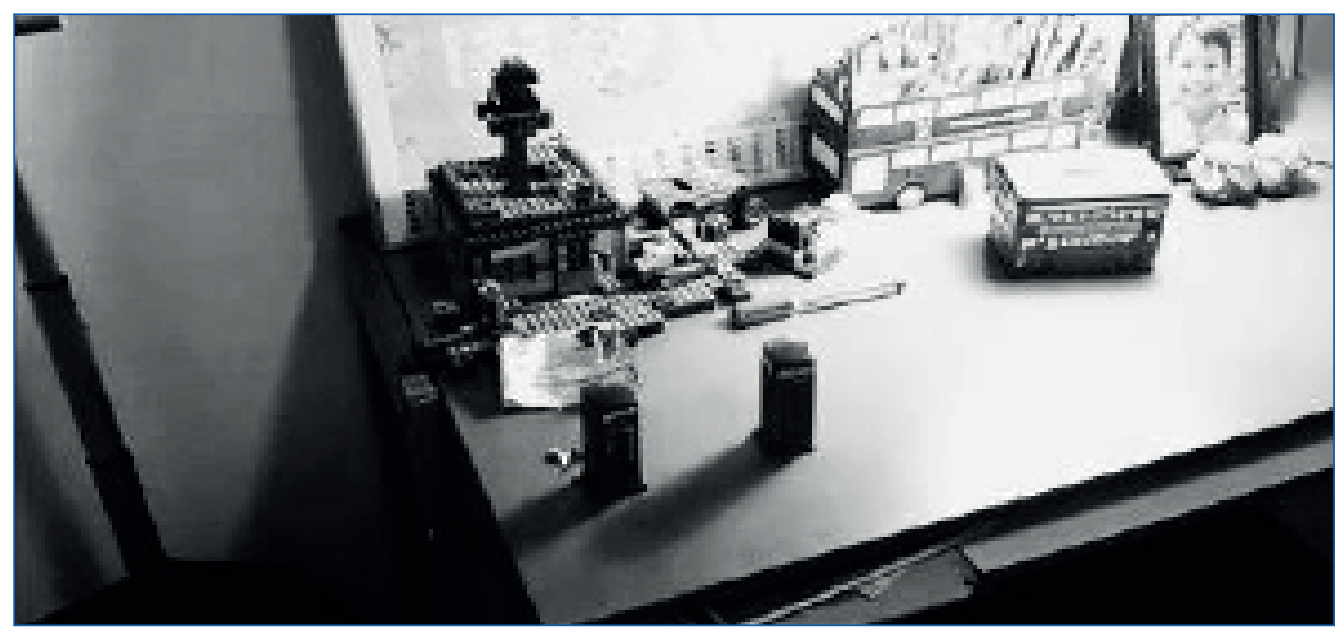

Figura 8. Escrivaninha do quarto de Vítor.

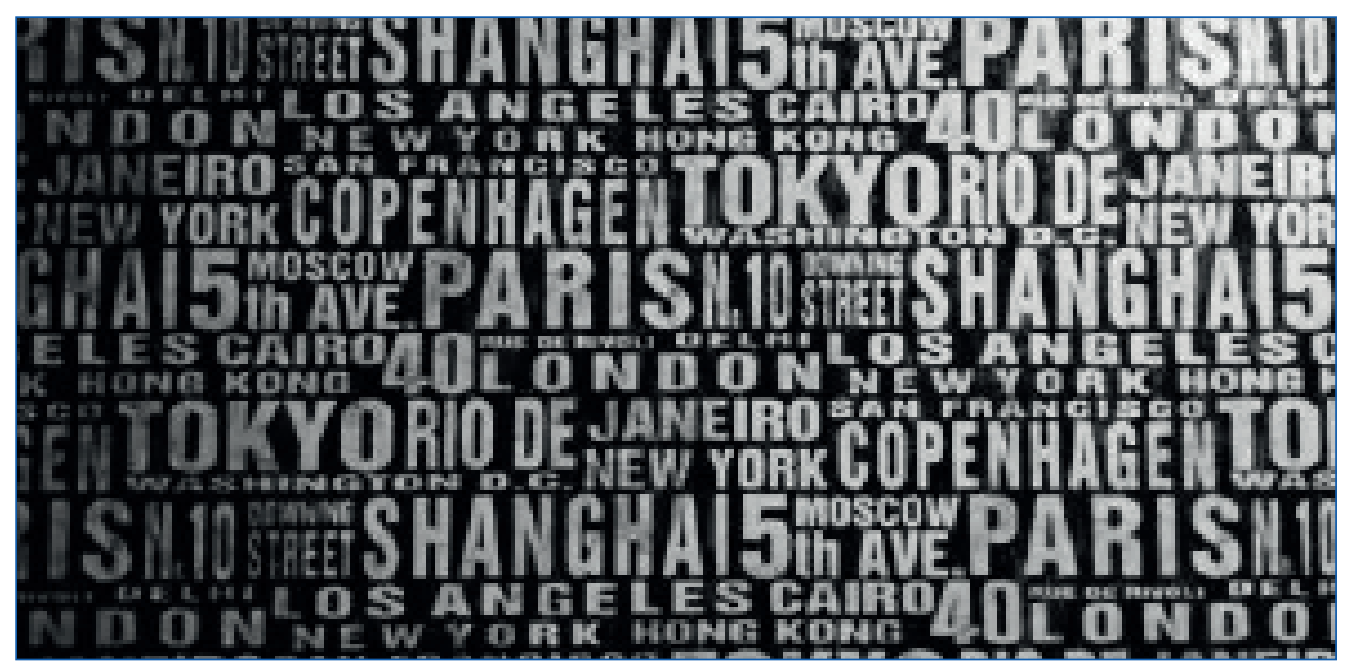

Figura 9. Papel de parede do quarto de Vítor. 
Assim, entre móveis e objetos, essas crianças têm a oportunidade de construir disposições que levem a pensar longe, bem como a acreditar que todos os lugares estão ao alcance das mãos, o que tornará mais provável uma trajetória internacional no futuro.

Contudo, se os objetos e espaços domésticos contribuem para o domínio (e o sentimento de domínio) do espaço e para o domínio (e o sentimento do domínio) do tempo, eles se encontram desigualmente distribuídos entre crianças de gêneros diferentes.

Em entrevistas com vendedoras e em uma pesquisa realizada nos catálogos disponíveis em lojas do setor de decoração infantil (CARVALHO, 2018), foram observadas diferenças significativas entre as versões masculina e feminina dentro de uma mesma linha de móveis para crianças. Nas versões masculinas, as marcas ofereciam escrivaninhas, enquanto, nas versões femininas, as escrivaninhas eram substituídas por penteadeiras.

Efetivamente, a pesquisa empírica realizada nos quartos visitados confirmou que as escrivaninhas eram mais frequentes nos quartos de meninos e, quando presentes no quarto das meninas, geralmente eram multifuncionais, ou seja, ofereciam também um espelho e gavetas para guardar acessórios de cabelo e maquiagem. Além disso, somente em um dos quartos masculinos visitados foi observada a presença de um espelho de corpo inteiro (Fig. 10).

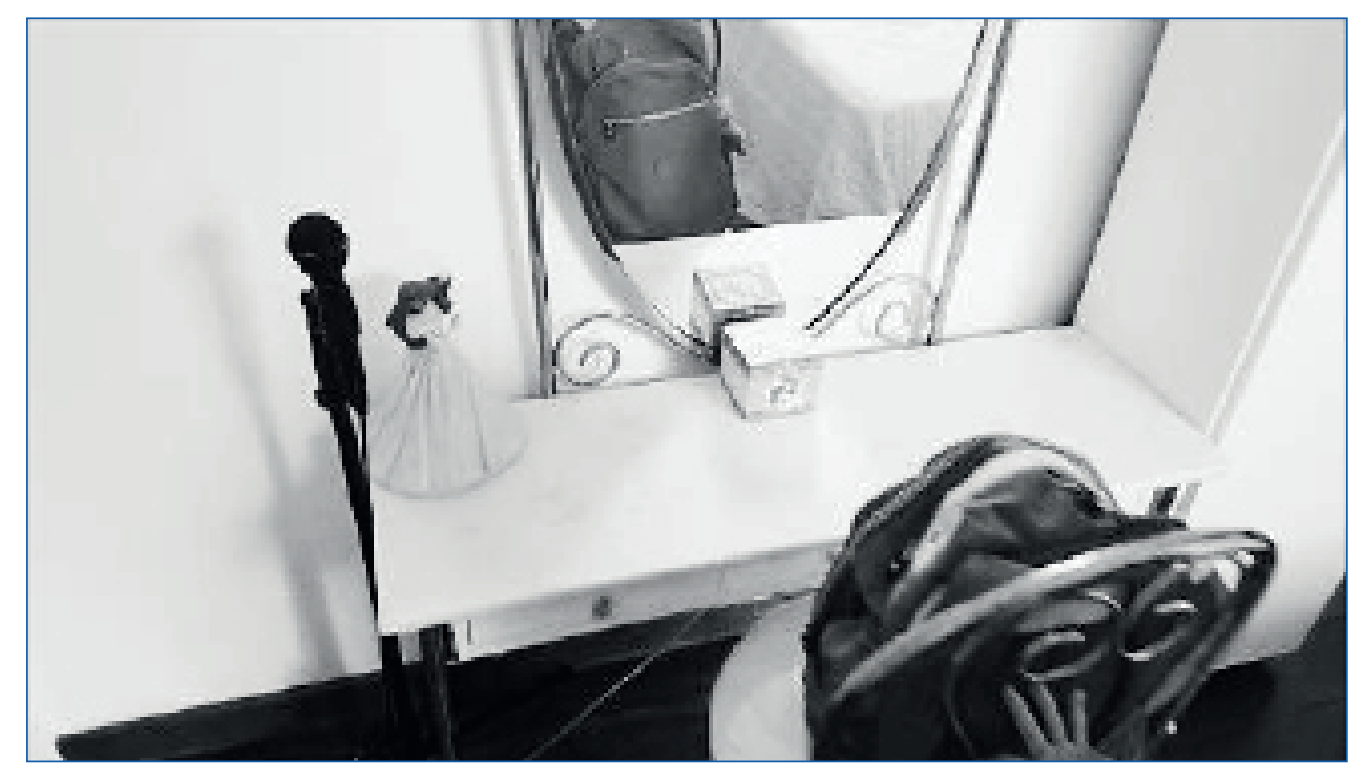

Figura 10. Penteadeira do quarto de Ana Beatriz, 8 anos.

Considerando o efeito simbólico de se reservar um espaço de estudos no quarto infantil, a substituição da escrivaninha pela penteadeira parece sugerir que são desiguais as expectativas endereçadas a meninos e a meninas no que diz respeito aos estudos, assim como são desiguais as condições materiais para a realização das atividades escolares. Além disso, a presença de espelhos no quarto das meninas e a quase absoluta ausência deles no quarto dos meninos incitam à reflexão sobre o papel que os espaços e objetos desempenham na construção social dos corpos, atribuindo-se à menina o trabalho de manutenção da aparência corporal, ao passo que, no caso dos meninos, a masculinidade é frequentemente inscrita corporalmente (ou incorporada) por meio da prática de esportes.

Resultado de uma seleção aleatória, a amostra pesquisada revelou-se desproporcional entre meninos (22) e meninas (9), razão pela qual este trabalho não pode concluir assertivamente sobre como e em que 
medida os quartos contribuem para a socialização de gênero. No entanto, a estratégia utilizada de comparar quartos de irmãos de sexos diferentes pretendeu mitigar as limitações do conjunto de dadose, assim, abordar, ainda que de modo tangencial, um aspecto significativamente relevante da decoração infantil. A seguir, são apresentados os dados referentes aos quartos de dois irmãos de sexos diferentes: Daniele (9 anos) e Leopoldo (6 anos).

O quarto de Daniele é decorado com cores suaves e detalhes minimalistas, em materiais que sugerem leveza: babados, espelhos e plumas. A sensação proporcionada pelo ambiente é de calma e segurança. Como mostram as fotografias a seguir, a escrivaninha de Daniele é multifuncional, conjugando espaço para a realização das atividades escolares com espaço para maquiagem (Figs. 11-13).

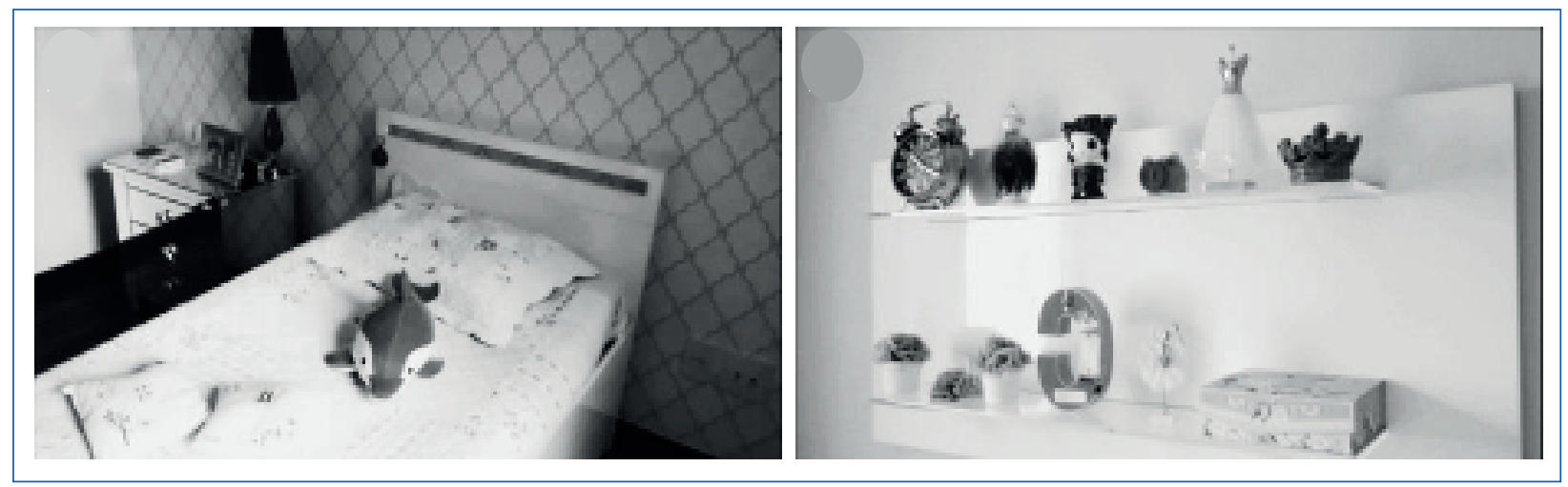

Figura 11. Decoração minimalista e em cores suaves.

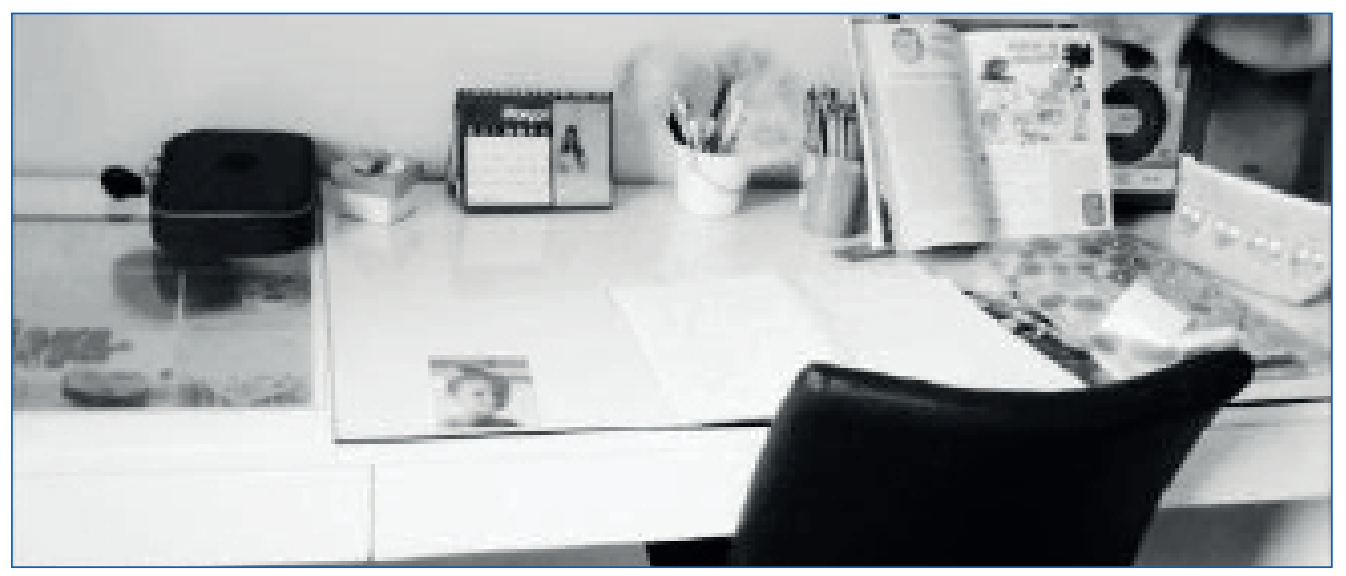

Figura 12. Escrivaninha multifuncional de Daniele.

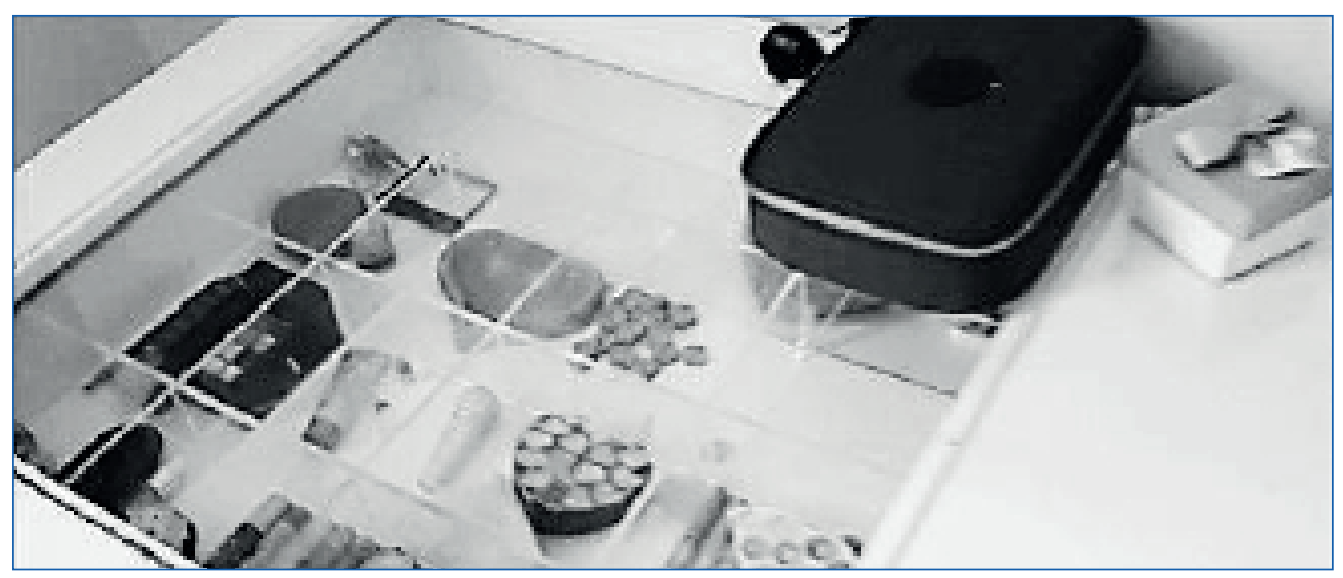

Figura 13. Escrivaninha multifuncional de Daniele. 
Por sua vez, o quarto de Leopoldo, irmão caçula de Daniele, conta com uma parede de escalada (ou rocódromo), que sugere a ideia de aventura, oportunizando a prática de uma atividade física individual com objetivo de alcançar o topo por meio da utilização da própria força para vencer perigos e obstáculos. Acima da escrivaninha do quarto de Leopoldo, encontra-se afixado um mapa-múndi com peças imantadas e em forma de avião. Ao lado, uma pequena biblioteca, móvel ausente no quarto de Daniele (Figs. 14 e 15).

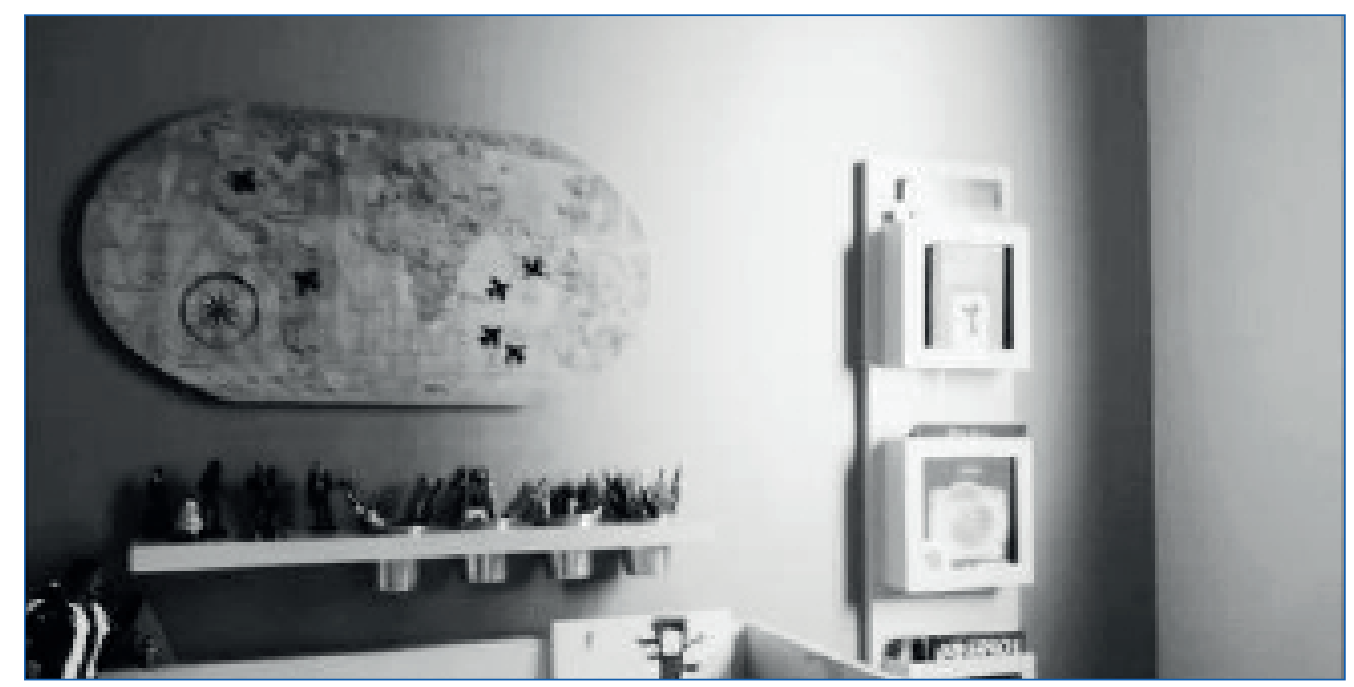

Figura 14. Quarto de Leopoldo, 6 anos.

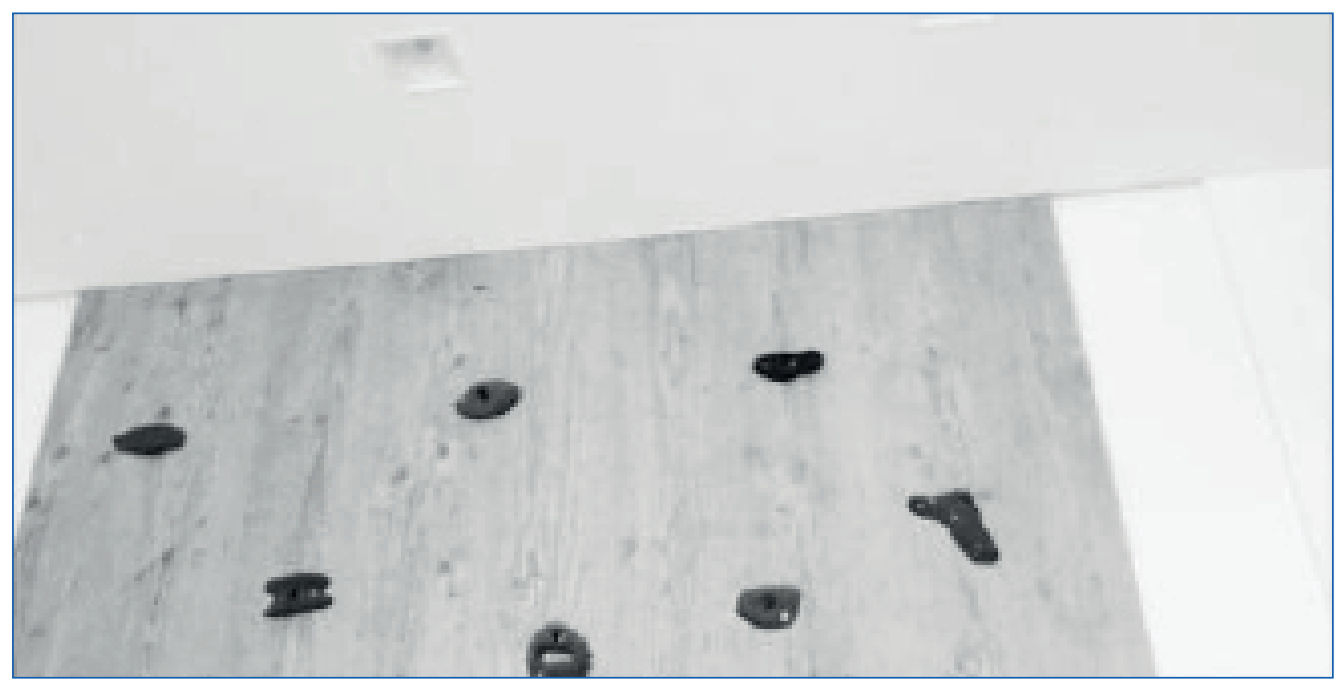

Figura 15. Parede de escalada do quarto de Leopoldo.

Esse conjunto de fotos permite demonstrar a gendrificação dos quartos, em que a decoração parece traçar uma fronteira simbólica que reserva o ambiente doméstico às meninas e o mundo aos meninos. Dessa maneira, aos meninos são concedidas possibilidades de um maior domínio do espaço (por meio da parede de escalada ou de objetos que são suporte do ethos cosmopolita) e um maior domínio do tempo (pelo culto à velocidade e também por serem eles os herdeiros privilegiados de alguns legados simbólicos). Ademais, as bibliotecas se mostraram aqui móveis predominantemente masculinos. A explicação para isso talvez seja a mesma da predominância da escrivaninha nos quartos dos meninos, ou seja, o reflexo de uma ampliação da expectativa parental mais alargada em relação à escolaridade dos meninos. 
Por sua vez, a socialização das meninas se mostrou mais circunscrita ao ambiente protegido do espaço doméstico, sendo o quarto feminino e seus espelhos um lugar propício aos cuidados com o corpo, que fazem parte do aprendizado social do tornar-se mulher.

Em suma, os quartos infantis constituem espaços marcados pela clivagem de gênero, espaços esses que podem ter por efeito a reprodução das desigualdades. Replicando práticas sociais consideradas femininas ou masculinas, os espaços íntimos contribuem para a construção de disposições, isto é, modos de pensar, de se portar, gostos e aspirações, que têm o efeito de uma profecia autorrealizável: a trajetória social de meninos e meninas, traçada entre móveis e objetos do espaço doméstico, teria mais chances de se cumprir.

\section{A Ação Interpretativa das Crianças}

Descrever os condicionantes da socialização familiar por meio da cultura material não significa ignorar a ação interpretativa das crianças. O agenciamento de espaços e objetos socialmente marcados não anula o agenciamento da própria criança. Para tanto, convém retomar a ideia de acomodação (MILLER, 2001), indicando que, além de uma construção familiar, esse cômodo é também uma criação infantil.

Proibida em muitas famílias, a colagem de adesivos em móveis e paredes do quarto pelas crianças é um exemplo do esforço de apropriação das crianças. Sobre os adesivos colados por Davi, a mãe comenta (Fig. 16):

[...] o armário é puro adesivo, né? [...] Eu tinha pensado em usar esse adesivo do [personagem] Thomas pra dar uma graça, mas acabou que ele ficou escondido. Se não falar, a gente nem percebe que tem, de tanto adesivo que ele foi colando em volta. Mas Davi foi decorando do jeito que ele mesmo achou. Às vezes, ele pega uma coisa que acha legal, vem e coloca na parede.

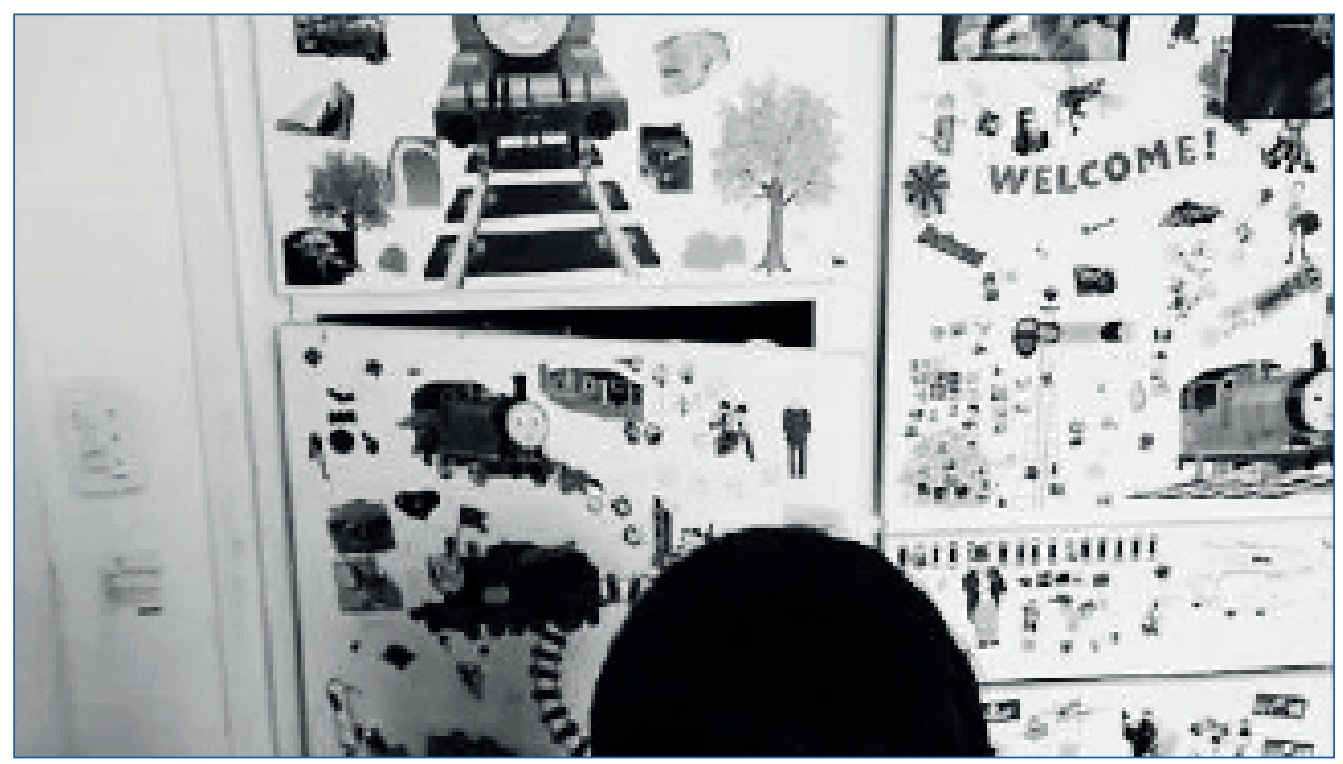

Figura 16. Adesivos colados por Davi nas portas do guarda-roupa.

Outro exemplo diz respeito à utilização das escrivaninhas, presente na quase totalidade dos quartos apresentados por crianças com mais de 6 anos, idade de entrada no Ensino Fundamental e, por consequência, da intensificação e da formalização dos deveres de casa (Fig. 17). 


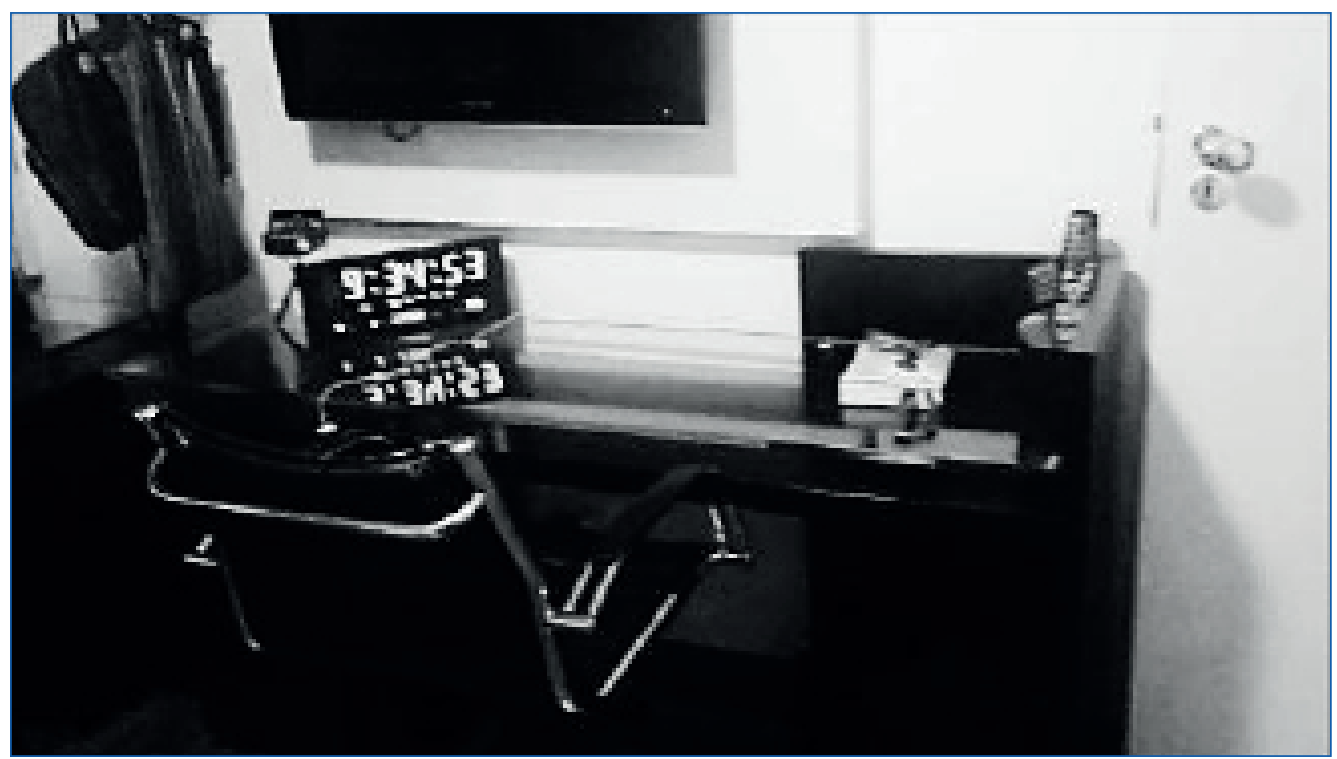

Figura 17. Escrivaninha do quarto de Fernando, 11 anos.

Apesar da importância conferida a esse móvel por pais e profissionais da decoração, muitas crianças relataram que preferem fazer o dever de casa em outro lugar, como a mesa da sala de jantar, já que as escrivaninhas vivem cheias de outros objetos: pequenas coleções, brinquedos ou livros literários (Fig. 18). Ao que parece, as crianças realizam uma apropriação desse móvel, que tende a desviá-lo de sua destinação inicial, transformando-o em um "palco de suas ocupações prediletas", como afirma Walter Benjamin, ao rememorar sua escrivaninha de infância: "Nada mais reconfortante do que permanecer assim, cercado por todos os instrumentos de minha tortura - vocabulários, compassos, dicionários - num lugar onde de nada valiam suas reivindicações" (1987, p. 120).

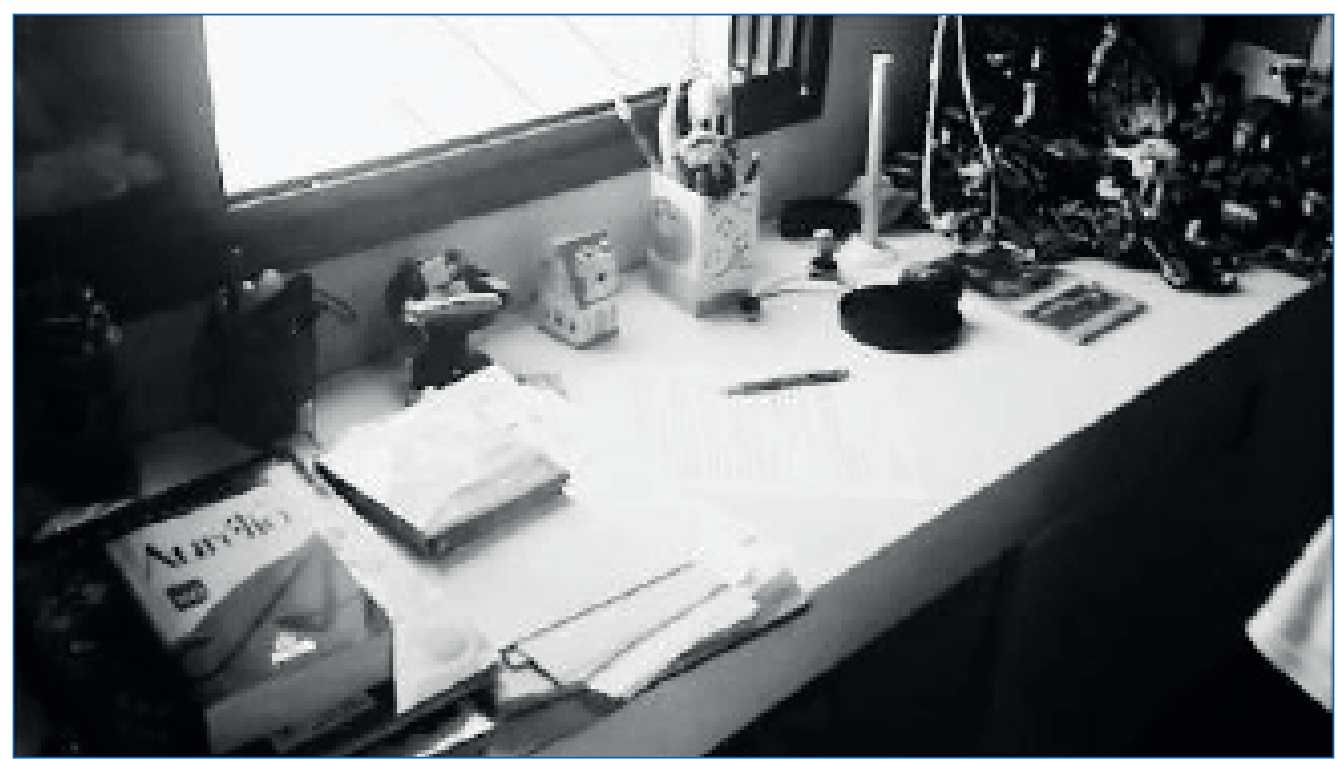

Figura 18. Escrivaninha de Abelardo, que prefere fazer os deveres escolares na sala.

Ficou nítido também o agenciamento das crianças em relação aos próprios procedimentos da pesquisa. Participando da entrevista com os pais, as crianças negociaram sentidos e versões. Raramente se dispuseram a participar do jogo de aparência dos adultos, no qual os pais usualmente sugerem: "Filho, 
mostre isso para ela!". A escolha do que mostrar e do que esconder foi realizada por cada criança a despeito de toda a lógica adulta. Em relação à pesquisadora, as crianças repactuaram, a todo instante, a permissão concedida de participar de seu espaço privado, ora impondo silêncios, ora mudando de assunto ou claramente declarando: “Sobre isso eu não quero falar!” Por outro lado, para espanto dos adultos (pais e pesquisadora), as crianças abriram gavetas e mostraram presentes ganhos "da menina de quem eu gosto" ou 'da minha namorada', traçando fronteiras singulares entre o público e o privado.

Além disso, as crianças renomearam uma das ferramentas de coleta de dados, em uma apropriação do procedimento de pesquisa. A proposta de uma "visita guiada" passou a ser chamada por diversas crianças de "tour pelo quarto", em referência a uma série de vídeos criados por youtubers mirins.

A confecção das plantas no aplicativo Magic Plan, recurso que despertou o interesse da maior parte das crianças, foi igualmente objeto de negociação. A primeira planta realizada durante a visita ao quarto de Tiago não foi aprovada por ele. Tiago reivindicou que, além dos móveis inseridos, a planta também representasse um carrinho de brinquedo, de cerca de 1,5 m, estacionado ao lado de sua estante. Trata-se, portanto, de uma criança que, ao apresentar seu quarto, questiona os critérios adultos: a cama, o criado-mudo e a estante de livros não são mais importantes do que o carrinho de plástico (Fig. 19).

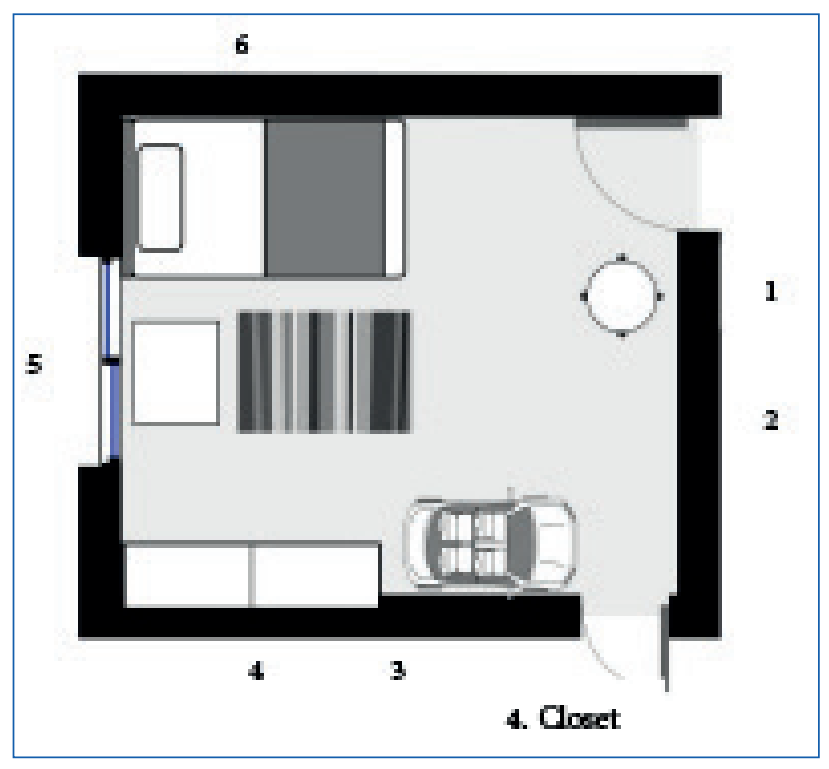

Figura 19. Planta do quarto de Tiago.

\section{Considerações Finais}

A pesquisa em espaços domésticos por vezes se assemelha a uma coleção de fatos corriqueiros: o espaço privado, chamado por Roche (2000) de "o porão da civilização", é um domínio em que a rotina, a inércia e a consciência fraca estão em sua influência máxima. Trata-se, afirma o autor, de um espaço onde prevalecem o silêncio sobre experiências comuns, uma temporalidade marcada por fracas rupturas e mudanças pouco visíveis. Um lócus em que predominam os hábitos, os costumes, as tradições que escapam da datação fácil e das divisões sociais reconhecidas. Imersos no espaço 
doméstico e no tempo cotidiano, os móveis e objetos decorativos das casas possuem a propriedade de saírem do nosso foco e jazerem periféricos à nossa visão, sem, contudo, deixar de condicionar nossas vidas (MILLER, 2001).

A pesquisa anteriormente descrita teve por objetivo justamente descortinar esse estado de coisas, pensando sobre como e em que medida a agência dos quartos infantis opera na socialização das crianças dos meios sociais favorecidos, contribuindo para a construção de disposições, ou seja, para a constituição de modos de sentir, pensar e se portar, que tendem a se preservar ao longo do tempo.

Nas famílias detentoras de capital econômico, a abundância de espaço e de pertences, assim como sua qualidade (percal 400 fios, veludo importado, madeiras nobres), transmitiria a ideia de tranquilidade, conforto e durabilidade. A liberdade quanto ao estilo de decoração experimentada por esse grupo e a possibilidade de trazer para o espaço do próprio quarto tudo aquilo que se deseja, por mais insólito e aparentemente irrealizável (como uma parede de escalada), parecem sugerir à criança as inúmeras possibilidades abertas por uma posição social elevada.

Por sua vez, nas famílias dotadas de capital cultural ou, ao menos, de uma "boa vontade cultural", a organização do espaço do quarto, em consonância com as demandas da cultura escolar, é ao mesmo tempo causa e efeito de uma forte simetria entre cultura escolar e cultura familiar, o que tende a contribuir para o sucesso escolar.

Contudo, localizar os espaços e os objetos dentro de um sistema simbólico e conjecturar os efeitos dessa rede de significações nas relações presentes e na construção de disposições não significa realizar uma aporia da causalidade que negligencie a agência das crianças e a diversidade de instâncias que coparticipam da socialização contemporânea.

A adesivação em móveis e paredes e a negação do uso da escrivaninha para a realização dos deveres escolares mostram como as crianças ressignificam seus quartos, ainda que sejam um espaço altamente permeável a instâncias como as mídias e a escola, além de ser um espaço privilegiado para a materialização das expectativas parentais.

\section{Contribuição dos Autores}

Problematização e Conceitualização, Carvalho CN e Nogueira MA; Metodologia, Carvalho CN e Nogueira MA; Análise, Carvalho CN e Nogueira MA; Redação, Carvalho CN e Nogueira MA.

\section{Notas}

1. Para um debate mais aprofundado sobre conceitos e questões teóricas ligados ao espaço doméstico como instância de socialização, ver Carvalho (2019). Se esse último texto, exclusivamente teórico e conceitual, mostra como a cultura do quarto abre uma agenda de pesquisas, o presente artigo descreve boa parte dos procedimentos empíricos e dos resultados de uma pesquisa de doutorado que tomou essa agenda como ponto de partida.

2. "Enclave" é um conceito da geografia política usado para designar territórios situados inteiramente dentro dos limites de outro território, mas que mantêm alguma autonomia política, social e/ou cultural.

\section{Referências}

AlmeIdA, A. M. F.; NOGUEIRA, M. A. A escolarização das elites: Um panorama. Petrópolis: Vozes, 2002. 
ALMEIDA, A. et al. As crianças e a internet-relatório da $2^{\text {a }}$ fase do trabalho: Entrevistas a crianças, pais e professores. Lisboa: ICS/Fundação Calouste Gulbenkian, 2011.

BAKHTIN, M. et al. Obras escolhidas II: Rua de mão única. São Paulo: Brasiliense, 1987.

BOURDIEU, P. (1979) La distinction: Critique sociale du jugement. Paris: Minuit, 2016.

BENJAMIN, Walter. Obras Escolhidas II: Rua de mão única. São Paulo: Brasiliense, 1987.

BUCKINGHAN, D. Crescer na era das mídias eletrônicas. São Paulo: Loyola, 2007.

CALDEIRA, T. P. Cidade de muros: Crime, segregação e cidadania em São Paulo. São Paulo: Editora $34,2000$.

CARVALHO, C. "Nascer em berço de ouro": Os quartos infantis como instância de socialização de crianças pertencentes a estratos sociais favorecidos. 2018. Tese (Doutorado em Educação: Conhecimento e Inclusão Social) Universidade Federal de Minas Gerais, Belo Horizonte, 2018.

CARVALHO, C. Quartos das crianças contemporâneas: A construção de um novo objeto de Pesquisa. Pro-Posições, Campinas, v. 30, 2019. https://doi.org/10.1590/1980-6248-2017-0176

CHRISTENSEN, P.; O'BRIEN, M. (eds.). Children in the city: Home neighbourhood and community. Londres: Routledge, 2003.

CRUBELLIER, M. L’enfance et la jeunesse dans la société française 1800-1950. Paris: Armand Colin, 1979.

DIBIE, P. O quarto de dormir: Um estudo etnológico. Rio de Janeiro: Globo, 1988.

ELIAS, N. Au-delà de Freud - Sociologie, psychologie, psychanalyse. Paris: Découverte, 2010.

ESTABLET, R. L'école est-elle rentable? Paris: PUF, 1987.

FRITH, S. The sociology of rock. Londres: Constable \& Company Limited, 1978.

GLEVAREC, H. La culture de la chambre - Préadolescence et culture contemporaine dans l'espace familial. Paris: DEPS, 2010.

HALBWACHS, M. La mémoire collective. Paris: Albin Michel, 1997.

IBGE [INSTITUTO BRASILEIRO DE GEOGRAFIA E ESTATÍSTICA]. Pesquisa Nacional de Amostragem domiciliar (PNAD), 2017. Disponível em: https://ww2.ibge.gov.br/home/estatistica/ populacao/estimativa2017/estimativa_dou.shtm. Acesso em: Jan 2018

FINE, A.; LABRO, S.; LORQUIN, C. Lettres de naissance. In: FABRE, D. Écritures ordinaires. Paris: Editions POL/Centre Georges Pompidou, 1993.

KELLERHALS, J.; MONTANDON, C.; GABEREL, P. E. Les stratégies éducatives des familles: Milieu social, dynamique familiale et éducation des préadolescents. Paris: Delachaux et Niestlé, 1991.

LANGE, A; MIERENDORFF, J. Method and methodology in childhood research. The Palgrave handbook of childhood studies. Londres: Palgrave Macmillan, 2009, p. 78-95. 
LE WITA, B. Mémoire familiale et mémoire généalogique dans quelques familles de la bourgeoisie parisienne. Paris: Ministère de la Culture/Mission du Patrimoine Ethnologique, 1983.

LE WITA, B. Ni vue, ni connue: Approche ethnographique de la culture bourgeoise. Paris: Les Editions de la MSH, 1988.

LIVINGSTONE, S. Young people and new media: Childhood and the changing media environment. New York: Sage, 2002.

LIVINGSTONE, S.; HELSPER, E. Gradations in digital inclusion: Children, young people and the digital divide. New Media \& Society, v. 9, n. 4, p. 671-696, 2007. https://doi.org/10.1177/1461444807080335

MARTUCCELLI, D. Grammaires de l'individu. Paris: Gallimard, 2002.

MENSION-RIGAU, É. L'enfance au château: l'Éducation familiale des élites françaises au vingtième siècle. Paris: Rivages, 1990.

MILLER, D. Home possessions. Oxford: Berg, 2001.

MILLER, D. Stuff. Polity, 2010.

MONTANDON, C.; LONGCHAMP, P. L'expérience de l'autonomie chez l'enfant. Une question récurrente dans la socialisation des enfants. Rapport présenté au FNS. Genève, Université de Genève, 2003.

NOGUEIRA, M. A. Convertidos e oblatos: Um exame da relação classes médias/escola na obra de Pierre Bourdieu. Educação, Sociedade \& Culturas, Porto, v. 1, n. 7, p. 109-129, 1997.

NOGUEIRA, M. A. Classes médias e escola: Novas perspectivas de análise. Currículo sem Fronteiras, v. 10, n. 1, p. 213-231, jan.-jun. 2010.

OPIE, I. A.; OPIE, P. Children's games in street and playground: Chasing, catching, seeking, hunting, racing, duelling, exerting, daring, guessing, acting, pretending. Londres: Clarendon, 1969.

PINÇON, M.; PINÇON-CHARLOT, M. Voyage en grande bourgeoisie. Paris: Journal d'Enquête, p. 98-112, 1997.

PINÇON, M.; PINÇON-CHARLOT, M. Sociologie de la bourgeoisie. Paris: La Découverte, 2000.

PRADO, R. L. C. O silêncio de grupos específicos de crianças em pesquisas. Educar em Revista, v. 33, n. 64, p. 215-230, 2017.

ROCHE, D. História das coisas banais. Rio de Janeiro: Rocco, 2000.

SEGALEN, M.; LE WITA, B. Chez-soi: Objets et décors: des créations familiales? Paris: Editions Autrement, 1993.

SEYMOUR, J.; MCNAMEE, S. Being parented?: Children and young people's engagement with parenting activities. In: WALDREN, J.; KAMINSKI, I. M. (eds.). Learning from the children: Childhood, culture and identity in a changing world. Oxford: Berghahn, 2012, pp. 92-107.

SINGLY, F. Le sens de la chambre personnelle pendant la seconde modernité. Le cas de l'adonaissance. 
In HUYNH, P. M. (dir.), Habitat et vie urbaine, changements dans les modes de vie. Paris: Puca,2006, p. 32-44.

SINGLY, F. Sociologie de la famille contemporaine. Paris: Armand Colin, 2010.

SINGLY, F.; THÉLOT, C. Racines et profils des ouvriers et des cadres supérieurs. Revue française de sociologie, p. 47-86, 1986.

\section{Sobre os Autores}

Cibele Noronha de Carvalho é pós-doutoranda na Faculdade de Educação da Universidade Federal de Minas Gerais (UFMG).

Maria Alice Nogueira é Professora titular do Departamento de Ciências Aplicadas à Educação e do Programa de Pós-graduação em Educação da Faculdade de Educação da Universidade Federal de Minas Gerais (UFMG).

Recebido: 14 Fev 2020

Aceito: 28 Abr 2020 